\title{
Examining Online Cheating in Higher Education Using Traditional Classroom Cheating as a Guide
}

\author{
Kerry Adzima \\ Pennsylvania State University of Erie, The Behrend College, Sam and Irene Black School of \\ Business, 5101 Jordan Rd., Erie, PA 16563 \\ kak38@psu.edu \\ DOI: 10.34190/JEL.18.6.002
}

\begin{abstract}
Academic dishonesty in higher education is a perverse problem affecting institutions of learning in many countries across the globe. More alarmingly, numerous studies have pointed to increasing rates of cheating and plagiarism over the past few decades offering a wide array of explanations and theories for this trend. A relatively new feature of both higher education and the discussion of academic dishonesty involves the growing market for online education. Within the last decade, online education has become a permanent fixture increasing its reach in education markets throughout the world. The trend of online education is seen as bringing with it a new set of opportunities and challenges related to academic dishonesty. With high rates of cheating already a well-documented problem in the traditional (face-to-face) learning environment, it is important to analyze how online education factors into this scenario. The goal of this paper is to provide the reader with a critical analysis of the current literature on academic dishonesty in online education and to propose areas for future research where gaps in the literature exist.
\end{abstract}

Keywords: academic dishonesty, cheating, online education, distance education, plagiarism

\section{Introduction}

Academic dishonesty in higher education has been a topic of concern for many decades. An abundance of research has been conducted that considers various forms of cheating, reasons for cheating, and ways to prevent it. It should be noted that academic dishonesty and cheating will be used interchangeably in this paper as is common in the literature (Trenholm, 2006/2007, p. 284). Until recently, most of this research has been conducted from a traditional (face-to-face) classroom perspective. However, in the last part of the twentieth century with the proliferation of the Internet, a new online educational environment has been created for which cheating can be analyzed. Online education, as defined by Allen and Seaman (2015), consists of 80 percent or more of a course's content being delivered online. On the other hand, hybrid or blended learning has 30-79 percent of a course's content being delivered online (Allen and Seaman, 2015).

In the past decade, many issues have been raised regarding the validity and quality of online education and the use of synchronous and asynchronous online learning in higher education. With synchronous online courses, students are typically required to participate in virtual class meetings at specific times. In this case, there is often an opportunity for students to interact with their instructors in real time and to get instant feedback on their progress. Alternatively, students can enroll in fully asynchronous online courses which do not require specific meeting times. In these courses, there are often weekly deadlines, but otherwise students work at their own pace. In addition, with some online education programs, students can participate in blended or hybrid courses where online learning is a component of the course with teachers and students still interacting in a physical classroom.

Many researchers claim that online learning presents a new set of opportunities and challenges for teachers and administrators when it comes to maintaining academic integrity (Kennedy et al., 2000; Rowe, 2004; Shachar and Neumann, 2010). At the extreme, some teachers and academic administrators worry that students can register for courses and then pay someone else to take the courses for them (Kasprzak and Nixon, 2004). For example, Hollis (2018) found that a web search using terms such as "student-for-hire" or "ghost student" revealed an expanding industry offering services dedicated to providing imposter students. Some teachers also assert that a lower student-perceived risk of getting caught makes it almost impossible to prevent student collaboration or the use of unauthorized materials leading to overinflated grades in the online environment.

Rowe (2004) and Bedford, Gregg, and Clinton (2011) have also suggested a variety of new opportunities that students can employ when engaging in academic dishonesty in the online environment such as waiting for another student to take the exam and then obtaining the answers using screenshots and emails, or students 
taking the exams together in pairs or groups. Students can also claim that they received fraudulent error messages to garner extra time to study or to get the answers from another student. In addition, many unauthorized test banks from popular textbook publishers are available online and if given enough time to complete an assessment, students may be able to look up answers or find similar questions to gain an unfair advantage.

Despite these new opportunities and challenges, online learning at the post-secondary level has seen steady growth since 2012, even as overall college enrollments have been declining. Specifically, online education in the United States increased by 5.6 percent from Fall 2015 to Fall 2016 bringing the number of students taking at least one distance course to 6,359,121, representing 31.6 percent of all students (Seaman, Allen, and Seaman, 2018, p.3). As colleges and universities continue to invest time and other resources into developing online courses and education programs, it will become increasingly important to study the prevalence of academic dishonesty in this environment and to continue developing strategies to prevent it (Cronan, Mullins, and Douglas, 2018; Vehviläinen, Löfström, and Nevgi, 2018; Ngo et al., 2018). Ensuring the validity of online courses is a crucial part of an institution's ability to successfully offer online degree programs and to support their continued growth and development. It should be noted that Massive Online Open Online Courses (MOOCs) were left out of this analysis due to the limited number of higher education institutions experimenting with this mode of delivery.

Although the literature that pertains to academic dishonesty in the online setting is still in its infancy, especially compared to the literature that examines traditional classroom cheating, the past two decades have ushered in an abundance of research with an expansive set of noteworthy topics and results. Given the upward trend in online education, it is important to begin examining what researchers are finding in the early stages of its development. The goal of this paper is to provide an overview of the research pertaining to academic dishonesty in the online environment for higher education. The paper is organized around four major themes (also referred to as categories) that emerged while conducting this review. The themes were broadly centered around the following issues: (1) Factors that potentially contribute to online cheating behaviors, (2) Student and faculty perceptions of online cheating behaviors, (3) The prevalence of cheating online compared to cheating in the classroom and (4) How cheating behaviors differ within proctored and unproctored environments.

\section{Defining 'cheating' or 'academic dishonesty' in the classroom and online.}

Before examining the literature pertaining to academic dishonesty in online education, it is useful to first establish how cheating is defined. It is interesting to note that many generic definitions of cheating seem to be applicable in both the face-to-face and online setting. For example, according to Cizek (2003) academic cheating is "any action that violates the established rules governing the administration of a test or the completion of an assignment; any behavior that gives one student an unfair advantage over other students on a test or assignment; or any action that decreases the accuracy of the intended inferences arising from a student's performance on a test or assignment." Although this author was referring to cheating in the classroom, one could certainly argue that this definition could be applied in an online setting as well. The difference however, lies in the methods or techniques students use to gain an unfair advantage. For example, in the classroom setting during an exam, a dishonest student may look at another student's test or use unauthorized notes hidden from the instructor. Although both behaviors are plausible, the inherent risks of getting caught are usually high enough to prevent most students from attempting these behaviors in the classroom. On the other hand, in the unproctored online setting, there is no way to confirm that the student registered for the course is taking the assessment, and if they are, there is no way to prevent him or her from getting unauthorized assistance. In both cases, the student's actions constitute "a behavior that gives one student an unfair advantage over other students on a test or assignment" but the perceived risks and methods to gain that advantage are different depending on the learning environment.

King, Guyette, and Piotrowski $(2009$, p.4) provided the following definition of cheating: "a transgression against academic integrity which entails taking an unfair advantage that results in a misrepresentation of a student's ability and grasp of knowledge." The authors then go on to mention that in the online context "this includes obtaining inappropriate assistance either from an online source or adjutant, plagiarism, and false selfrepresentation." In this case, the definition of cheating could once again be applied to both the classroom or online environment. However, in this example, King, Guyette, \& Piotrowski (2009) make it a point to specify how the cheating methods may differ or be more pronounced in the online environment. 
To better understand how students perceive the concept of cheating, Raines et al. (2011) conducted a qualitative study to examine the definition of cheating in the online environment from a student's perspective. The findings of their study revealed that most students believe that breaking the rules, dishonesty, and not doing the work themselves are behaviors that constitute cheating. The authors also found that students perceived there to be a difference "between the expectations in an online and classroom-based course" and therefore students are "influenced by the boundaries of the learning behaviors established in each course by the faculty." More specifically, students mentioned that in online courses they are often allowed to look at course notes or the textbook when taking assessments, but they are not allowed to look up answers online. Raines et al. (2011) conclude that online instructors need to be very careful and precise when defining the acceptable learning behaviors and expectations regarding assessment practices in their courses.

In summary, cheating occurs when students engage in dishonest behavior. What constitutes dishonest behavior needs to be clearly defined generally by university or college honor codes and defined in specific terms by course instructors. Dishonest behavior in both the face-to-face and online settings results in the student gaining an unfair advantage which misrepresents their true knowledge and abilities. The new opportunities and challenges pertaining to academic dishonesty in the the online environment are due in large part to the absence of physical proctoring of course work. This can lead to student identity issues, the use of unauthorized materials or assistance, and the perception that there is a lower risk of getting caught.

\section{Methodology}

Given that the definition of cheating remains intact when discussing different learning environments, this study was conducted by first considering cheating behaviors in the classroom and establishing a set of parameters or categories for which these behaviors could be studied in the online environment. Key word searches were conducted using a variety of databases (ProQuest, SpringerLink, Education Information Resources Center (ERIC), JSTOR, and EDUCAUSE Library.) The initial search used ERIC and the words 'cheating,' AND 'academic dishonesty' OR academic integrity. This search provided an extensive list of 242 articles that mainly focused on classroom cheating. Articles that were not from academic peer-reviewed outlets or before 1990 were not examined. While examining the remaining articles, the first category for analyzing cheating in the online environment was established: "the factors that contribute to cheating behaviors." This category has been well-researched in the literature for the face-to-face learning environment. More specifically, the factors that contribute to classroom cheating have been classified as individual factors (also known as demographic and personality factors), and situational (also referred to as contextual) factors (McCabe and Trevino, 1997; Crown and Spiller, 1998; McCabe, Trevino, and Butterfield, 2001). Once the main factors that contribute to classroom cheating were established, additional key word searches were conducted using the aforementioned databases. These searches focused more specifically on the online environment using thefollowing key words:: 'online education,' OR'distance education,'OR 'online learning,' OR 'online academic integrity' OR 'distance learning,' OR'asynchronous online education,'OR 'synchronous online education,' OR'academic dishonesty in online education,'OR 'cheating online,' OR 'online plagiarism.' In this search, 78 articles from 2000 to 2019 were found. All articles that listed individual factors or situational factors that contribute to online cheating behaviors were analyzed. After excluding articles that only discussed online cheating issues using anecdotal evidence, or for which online cheating was not the main focus of the paper, 63 articles remained and were analyzed.

While examining the above-mentioned academic articles that referenced online cheating factors, the next category to emerge as a prevalent issue in this literature was student and faculty perceptions of online cheating behaviors. This category emerged as relevant because social norms theory, which suggests that an individuals' behavior is influenced by misperceptions of how their peers think and act, has been used to examine student and faculty perceptions of academic misconduct in the classroom. In particular, Hard, Conway, and Moran (2006) used social norms theory to study student and faculty perceptions of academic misconduct and found that students overestimate the frequency of cheating by their peers in the classroom setting. Since students and faculty are found to overestimate the amount of academic misconduct in a face-to-face setting, the perception that it is easier to cheat in the online setting could conceivably enhance these beliefs even further and lead to more cheating online. Examining student and faculty perceptions of online cheating behaviors is thus important from both a theoretical and practical standpoint. 
The third category or theme to emerge when conducting this review was the prevalence of cheating online compared to cheating in the classroom. The papers reviewed in this category compared the occurrence of cheating in the classroom to cheating online using self-reported survey methods.

The final issue examined in this paper was the difference in cheating behaviors between proctored and unproctored environments. Because of the new opportunities to cheat and the challenges that instructors face when trying to prevent cheating, it is important to analyze those papers that look directly at how the absence of physical proctoring influences the rate of cheating. These papers were grouped by empirical approach first and then by the authors' results. The remainder of this paper examines each of these four major themes.

In summary, when conducting a systematic review, it is important to clearly define the inclusion and exclusion criteria upon which the review is based. As mentioned above, all articles that referenced one of the four major themes were included in this review. The methodologies used in these papers included: self-reported surveys and randomized or experimental designs. These studies included students who took both asynchronous online classes and those students who took face-to-face classes that had an online component. In addition, both qualitative and quantitative methods were appropriate and therefore included as acceptable research designs when selecting papers for review. Papers that examine online cheating only began to appear in the literature from 2000 onwards and thus the timeframe for this study was predetermined. The exclusion criteria were based upon publication type and relevance to the four major themes. Working papers, conference proceedings, policy briefs, and popular press articles were not included in this analysis. Papers that mentioned online cheating but did not focus on one of the four major themes were excluded. For example, papers that examined the use of online tutorials to prevent cheating or papers that focused on how cheating impacted the effectiveness of online learning were not relevant to this study and thus excluded.

\section{The factors that may contribute to cheating behaviors}

While there are several factors related to academic dishonesty, most studies that analyze cheating have broadly separated these factors into two types: individual factors (also known as demographic and personality factors), and situational (also referred to as contextual) factors (McCabe and Trevino, 1997; Crown and Spiller, 1998; McCabe, Trevino, and Butterfield, 2001). For comparison purposes, papers that examine the individual and situational factors for both classroom cheating and online cheating are discussed below.

\subsection{The individual factors that contribute to cheating behaviors in the face-to-face classroom}

Studies that analyze the individual factors contributing to academic dishonesty in the face-to-face classroom are abundant. Variables such as age, gender, intellectual ability, ethnicity, college major, extracurricular participation, employment status, level of schooling and self-esteem have been considered as potentially important factors that may be correlated with cheating behaviors (Iyer and Eastman, 2006). Of these variables, the three that have consistently been shown to have an impact on academic dishonesty in the traditional classroom are age, gender, and intellectual ability. Specifically, both younger students and male students are shown to cheat more often, and in general, students with higher intellectual abilities have been found to engage in less academic misconduct compared to their peers with lower ACT scores, intelligence and grade point averages (GPA's), (Whitley, Nelson, and Jones, 1999; McCabe and Trevino, 1997; Athanasou and Olasehinde, 2002; Underwood and Szabo, 2003; Simon et al., 2004; Lau and Haug, 2011; Kisamore, Stone, and Jawahar, 2007.)

Other studies, such as those that look at individual factors related to personality, have received less attention in the academic dishonesty literature in the face-to-face classroom. However, Simha and Cullen (2012, p.29) found that students are more likely to cheat when they are categorized as 'impulsive, risk taking, attention-seeking, low in responsibility, and tend to be externals on the locus of control measure.'

\subsection{The individual factors that contribute to cheating behaviors in the online environment}

Research that analyzes the individual factors contributing to academic dishonesty in the online environment is less abundant and the findings are a bit more mixed compared to those of the traditional classroom setting. For example, Lanier (2006) analyzed 1,234 self-reported cheaters in traditional and online courses and found that males are more likely to cheat online and that older students, married students, graduate students and students with a higher GPA are less likely to self-report cheating in their online courses. Similarly, Miller and Young-Jones (2012), Kidwell and Kent (2008), and Peled et al. (2019) found that older students are less likely to cheat but in 
contrast to Lanier (2006), these authors observed no significant difference in cheating levels based on gender. In addition, Costley (2017) is the only paper found to exclusively survey online students in order to analyze student characteristics in relation to academic misconduct. The author reported that neither age nor gender are related to cheating behaviors in a Korean online learning environment but that 'students who are in their earlier years of study are more likely to cheat than their senior peers,' (Costley, 2017, p.320).

Interestingly, and in contrast to most studies, Watson and Sottile (2010) surveyed 635 online and face-to-face undergraduate and graduate students and found that more females (37.8 percent) self-report cheating in online courses compared to males (20.8 percent). Finally, Peled et al. (2019) also analyzed the relationship between cheating, personality traits, and motivation and found that conscientiousness, agreeableness, intrinsic and external motivation and emotional stability are all predictors of lower levels of academic dishonesty online. Additionally, the authors noted that "online courses are not a predominant factor in the prediction of misbehavior."

\subsection{The situational factors that contribute to cheating in the face-to-face classroom}

Over the past several decades, many studies have looked at how students feel about cheating and how those feelings relate to their behavior in a face-to-face classroom. Some studies have revealed a trend in the student culture becoming more accepting of academic misconduct (Brimble and Stevenson-Clarke, 2006). Some students even see cheating as a way to maintain a level of fairness since they believe so many of their peers are engaging in dishonest behavior (Engler, Landau, and Epstein, 2008). On the other hand, some students selfreport a lack of time due to time-consuming commitments unrelated to schooling such as work, family, and extracurricular activities as a factor leading to dishonest behavior (Owunwanne, Rustagi, and Dada, 2010). In addition to time pressures, many students feel pressure to achieve high grades. This type of pressure may be self-inflicted or students may feel pressure from their families or employers who offer to pay for their schooling as long as they maintain a certain level of achievement.

Other studies such as and Smyth and Davis (2004) have shown that although approximately 90 percent of students report that cheating is wrong, a large majority of those students (75 percent and 45 percent, respectively) admit to cheating anyway. Many theories have been developed to try and explain this contradictory behavior. For example, Simha and Cullen (2012) suggested that deterrence theory may explain why students continue to cheat even after admitting they know it is wrong. Specifically, deterrence theory demonstrates that unethical behavior can be discouraged by increasing both the perceived probability of being caught and the severity of punishment for the behavior (Buckley, Wiese, Harvey, 1998). Therefore, if students perceive a small chance of getting caught in conjunction with little to no punishment when they do, this may increase their willingness to engage in dishonest behavior. In addition, deterrence theory is applicable when considering student perceptions of peer behavior. For example, researchers have suggested that when students believe their peers are cheating without penalty, they will then be more inclined to engage in that behavior themselves (McCabe, 1992; McCabe, Trevino, and Butterfield, 1999).

Another theory that gained popularity in the 80 's and 90's related to academic dishonesty was that of neutralization. Neutralization is defined as 'a process of explaining or legitimizing one's dishonest behavior rendering it neutral or no longer dishonest,' (Wideman, 2008, p.4). This theory predicts that students justify their dishonest behavior by deflecting blame and arguing that special circumstances caused them to cheat which protects them from being held accountable or feeling guilty (McCabe, 1992). According to Meng et al. (2014, p.67), 'blaming others and attributing problems to external sources are prime examples of neutralizing attitudes that enable cheating.'

Recently however, researchers are starting to find that cheating is becoming more of a cultural norm and that many students no longer feel the need to provide justification for their dishonest behavior (McCabe, Butterfield, and Trevino, 2012). For example, Stiles, Wai Wong, and LaBeff (2018) proposed that age cohorts or generations may help to explain this cultural shift. In particular, the authors study academic entitlement, a primary characteristic associated with millennials, as a potential contributing factor to cheating. Academic entitlement is defined as 'preferring to receive more from one's academic experience than one's peers and preferring to get more from one's academic experience than one gives to it' (Miller, 2013, pp.655-656). Using a study of 506 undergraduate students, Stiles, Wai Wong, and LaBeff (2018, p.829) concluded that 'academic entitlement is significantly related to participants' reports of cheating on major exams, weekly quizzes, class assignments (term papers, lab assignments, homework assignments), and helping others to cheat.' 
Another recent trend that is receiving attention in the academic dishonesty literature deals with contract cheating. This form of cheating was defined by Clarke and Lancaster (2006) as 'the submission of work by students for academic credit which the students have paid contractors write for them.' Research by Bretag et al. (2018) investigated a variety of outsourcing behaviors in an Australian University and found that the following three variables were significantly correlated with contract cheating: dissatisfaction with the teaching and learning environment, the perception of multiple cheating opportunities and speaking a language other than English at home. It should be noted that the authors did analyze the mode of study as a correlating factor, however, only a small number of online only students were surveyed making generalizations problematic.

\subsection{Applying the theories that relate to situational factors in the classroom to the online setting}

The situational factors associated with cheating behaviors discussed above have been primarily studied from the standpoint of a face-to-face classroom. However, it is plausible that deterrence theory, neutralization and academic entitlement all play a role in the cheating behaviors of online students as well. To understand how these theories can be applied, it is important to first discuss how the online environment can potentially contribute to academic misconduct. One characteristic of online learning that may correlate with cheating behaviors is the higher degree of anonymity in this environment compared to a face-to-face classroom. Although some students in large traditional classrooms can also maintain some degree of anonymity if they choose, the opportunity to remain anonymous in the online environment is arguably much higher.

Several articles claim that the lack of face-to-face contact between teachers and students creates a psychological barrier that makes students feel as if dishonest behavior is more acceptable (Heberling, 2002; Rowe, 2004; Stuber-McEwen, Wisely, and Hoggatt, 2009; Sande and Xuetao, 2018). Since anonymity can prevent students from developing a connection with their instructor, it may remove some of the guilt students feel about the act of cheating. In addition, the distance creates a perception that it is easier to cheat online because of increased opportunities and a diminished chance of getting caught (Chapman, 2004; McNabb and Olmstead, 2009). Using the same line of reasoning, the perception that it is easier to cheat online may solidify or strengthen the belief that the students' peers are also cheating more often and without consequences (Styron and Styron, 2010; Costley, 2018). Anonymity is thus a potential contributing factor to online cheating that relates to both deterrence theory and neutralization theory.

Another issue associated with anonymity that is shown to increase instances of academic dishonesty is the students' perception that they are receiving a low-quality educational experience (McCabe, Butterfield, and Trevino, 2012). Although there are many papers that address this issue from an offline perspective (Owunwanne, Rustagi, and Dada, 2010; Beasley, 2014), it is possible that the attributes of online learning can intensify this notion due to the feeling of isolation many students encounter in this environment. Accordingly, Costley (2017) found that online students are more likely to engage in dishonest behavior when they are not satisfied with or interested in the course they are taking and student dissatisfaction is often related to poor course design (Costley, 2018; Arnold, 2016; Brent and Atkisson, 2011). Students may consider courses to be poorly designed if the assignments or topics covered are not engaging or relevant to the student's learning goals or because the courses are perceived as being too difficult or time consuming. In addition, online students may turn to academic dishonesty if they feel the instructor has provided insufficient feedback, guidance, or support and if they do not believe the instructor has implemented adequate safeguards against cheating (Owunwanne, Rustagi, and Dada, 2010; Beasley, 2014). In general, if students believe the online environment is to blame for the poorly designed course, this could be a 'special circumstance' that leads to academic dishonesty as predicted by neutralization theory.

Another factor that may contribute to dishonest behavior is the students' lack of knowledge or misunderstanding of their institutions academic integrity policy. Although this can be a problem for all types of dishonest behavior (in both the face-to-face and online environments), it is most often referenced regarding plagiarism (McMurtry, 2001). In particular, many authors have found that 'plagiarism is often misunderstood by students' (Brent and Atkisson, 2011, p.656.) In fact, some students do not know how to appropriately cite sources and therefore the act of plagiarism is inadvertent. In other instances, students develop an attitude of indifference towards plagiarism and therefore it becomes more of a deliberate act (Auer and Krupar, 2001; Stiles, Wai Wong, and LaBeff, 2018). More alarmingly, students may know that they cheated or plagiarized but falsely and intentionally claim they were not given enough information to fully understand what was expected of them (Brimble and Stevenson-Clarke, 2005; Ryan et al., 2009; Beasley, 2014). 
When it comes to plagiarism in the online environment, a lack of knowledge or a misunderstanding of academic integrity policies can still be a contributing factor, however, anonymity can potentially lead to additional or enhanced concerns for this type of misconduct. More specifically, research has shown that the lack of a personal relationship between the teacher and student may lead to higher levels of plagiarism online (Ewing, Anast, and Roehling, 2016; Şendağ, Duran, and Fraser, 2012). For example, in a face-to-face course, students often meet with their instructors to discuss an assignment such as a research paper. During these meetings, instructors can ask questions and engage in a dialogue that would make it hard for students to misrepresent someone else's work as their own. When students submit a rough draft in the online environment, using detection software may help to curb plagiarism, however, without face-to-face contact, it becomes harder to establish whether students are submitting their own work or the work of a friend, or engaging in contract cheating. As deterrence theory predicts, the lack of direct contact may increase online cheating behaviors if students perceive an increased opportunity to engage in plagiarism with lower chances of being caught. In addition, although the punishments for plagiarism through contract cheating have been found to be quite severe including suspension and expulsion (see for example, Tennant and Duggan, 2008), students have been found to have a more relaxed attitude when it comes to contract cheating. For example, Newton (2015) found that students expressed the opinion that a more lenient penalty than expulsion is appropriate in cases of contract cheating. These relaxed student attitudes toward contract cheating and how they relate to the idea of academic entitlement in the online environment needs to be further explored in the literature.

Overall, anonymity can be a potential situational factor contributing to dishonest behavior in online learning. The lack of face-to-face contact between the teacher and student can enhance the perception of increased opportunities to cheat and the perceptions of high levels of peer cheating. Deterrence theory, neutralization and academic entitlement all provide explanations for the occurrence of academic dishonesty and all three are applicable in both the face-to-face and online learning environments.

\section{How student and faculty perceptions of online cheating prevalence impact cheating behaviors}

Ten articles were found that directly compare student perceptions of academic dishonesty in online versus faceto-face courses. Five of these articles concluded that students believe cheating is easier or more prevalent in online courses, three articles revealed mixed results, and two articles revealed evidence that students see no difference in the incidence of cheating between the two modes of delivery. Finally, one article was included in this section that looks at student perceptions of the proctored versus unproctored environment. The articles are discussed in more detail below and are grouped together based on the authors' conclusions.

\subsection{Student Perceptions of Online Cheating Behaviors}

In a widely cited paper, Kennedy et al. (2000) surveyed behaviors and perceptions of 172 online and face-to-face students at the undergraduate and graduate levels and revealed that 57 percent believe that cheating would be easier in online classes. However, the authors also mention that experience taking an online course reduces that perception. Similarly, King et al. (2009) reported that of the 121 undergraduate business students surveyed, 73.6 percent held the perception that it was easier to cheat online compared to a face-to-face classroom. In this sample, the authors did not find any statistically significant difference in the responses between students who had experience taking online courses and those who did not. Miller, Shoptaugh, and Parkerson (2012) surveyed 639 undergraduate and graduate students from two different universities with varying majors and showed that 57.2 percent agreed that cheating online was easier than cheating in a face-to-face setting.

Watson and Sottile (2010) surveyed 635 online and face-to-face undergraduate and graduate students. The responses indicated that the students believed their peers were five times more likely to cheat in an online class than in a face-to-face class and that they themselves are four times as likely to cheat in an online class. StuberMcEwen, Wisely, and Hoggatt (2009) surveyed 225 online and face-to-face (upper and lower division) undergraduate students and members from both groups believed more cheating occurs in online courses.

The three articles that reveal mixed results are Charlesworth, Charlesworth, and Vician (2006), Harmon, Lambrinos, and Buffolino (2010) and Watters, Robertson, and Clark, (2011). Charlesworth, Charlesworth, and Vician (2006) surveyed a sample of 175 students in a web-enhanced first year chemistry course and found that although 40 percent of students think online assessments encourage more cheating, another 40 percent think there is no difference. Harmon, Lambrinos, and Buffolino (2010) used a sample of 100 students from both online 
and face-to-face introductory economics courses and found that 59 percent of students perceive the frequency of overall cheating to be about the same in online and face-to-face formats. Watters, Robertson, and Clark (2011) used survey responses from 98 undergraduate accounting majors from two universities and reported that 45 percent believe cheating is more prevalent online, 21 percent believe it is not more prevalent, and 34 percent give a response of no opinion. The authors concluded that it is not clear whether most students perceive more cheating to be taking place in the online environment.

Hart and Morgan (2010) and Black, Greaser, and Dawson (2008) report findings that suggest students do not perceive a difference in the levels of cheating based on mode of delivery. Specifically, Hart and Morgan (2010) used survey responses from 44 students in an online cohort and 330 students from a traditional classroom in a registered nurse to baccalaureate in nursing (RN-BSN) program and reported very low levels of cheating from both formats. In addition, there was no significant difference found between the two groups regarding how frequently they think plagiarism on written assignments, inappropriately sharing work in group assignments, or cheating during tests or examinations occurs in their program. The authors also noted that overall, their respondents were mostly white, female, married and planned to continue their education in graduate school which likely influenced the results.

Black, Greaser, and Dawson (2008) surveyed 1,068 undergraduate students primarily aged 18-22 taking an online psychology course. The authors reported that 81 percent of the students believe that cheating is no more prevalent in their online courses than their traditional courses. Although the authors did not provide information specific to the sample, they note that 'reviews of enrollment data have shown that students in these online courses are generally in later academic years and have higher GPA's,' Black, Greaser, and Dawson (2008, p.24).

Finally, Spaulding (2009) looks at the student perception of cheating from the perspective of the proctored versus unproctored environment. Here, the author surveyed a sample of 103 undergraduate students (85 percent of which were female) from two sections of a technology integration course in a teacher education program. The courses only differed by how assignments and tests were delivered. In one section, all assignments and tests were completed in the classroom with a proctor while in the other section all assignments and tests were completed outside of the classroom and without a proctor. The sample contains 76 students from the proctored testing and assignment format and 27 students from the unproctored format. The author observed no significant difference in students' perception of the academic integrity of their own behavior or other students' behavior based on how the assessments were delivered.

\subsection{Faculty Perceptions of Online Cheating Behaviors}

There are four articles found to analyze faculty perceptions of online versus traditional student cheating behaviors. The earliest article by Kennedy et al. (2000) reported that 64 percent of the 69 faculty members surveyed believe cheating is easier online. However, they also observed that experience teaching an online course reduced that percentage. This is consistent with Yates and Beaudrie (2009) who conducted faculty interviews and reported that faculty members who do not teach online believe academic dishonesty is more likely to occur in an online course. In contrast, they found that faculty who have taught fully online courses perceived there to be no significant differences in test scores between the two environments. Using 76 survey responses of faculty teaching online and in-class courses, McNabb and Olmstead (2009) concluded that those faculty who teach online did not see a discernable difference between instances of cheating in online versus the in-class format. Kelley and Bonner (2005) used a sample of 296 faculty and 131 administrators in their survey of academic dishonesty perceptions. Of their respondents, 52.2 percent either used the web in their courses or had taught online. Of this population, 65.6 percent claimed 'they did not perceive an increase in the amount of academic dishonesty in their courses,' Kelley and Bonner (2005, p.48).

In summary, student and faculty perceptions play an important role in understanding cheating behaviors. Social norms theory says overestimations of problem behaviors in our peers will cause us to increase our own problem behaviors. Hard, Conway, and Moran (2006) found that students overestimate the amount of cheating that occurs in traditional classrooms and five of the ten articles analyzed here showed that students either perceive cheating to be easier or more prevalent online. However, half of the articles revealed mixed results or concluded that student's see no difference in the prevalence of cheating in the two environments. Given the conflicting results from these studies, additional research is needed for generalizability. In addition, although there is only a small sample of articles that focus on faculty perceptions of online versus face-to-face cheating behaviors, the 
consensus from these articles revealed that faculty perceptions vary depending on their online teaching experience. More specifically, faculty with online teaching experience in these studies do not believe cheating is more prevalent in the online environment.

\section{The prevalence of cheating online compared to traditional cheating in the classroom}

There are eight articles reviewed in this paper that employed self-reported survey methods to directly compare the cheating behaviors of students in the online and face-to-face environments. Two of these articles revealed that online cheating is more prevalent, two found that there is no difference, and four concluded that cheating is less prevalent online. The articles are discussed in more detail below.

Lanier (2006) examined survey responses from 1,234 undergraduate and graduate students and observed that students are more likely to cheat online. Specifically, 41.1 percent of students admitted to cheating online while only 4.4 percent reported cheating in a face-to-face course. As mentioned previously, Miller, Shoptaugh, and Parkerson (2012) found that of the 639 students (531 undergraduates and 109 graduates) surveyed, 53.7 percent believed it is easier to cheat online. To test the accuracy of their results, they looked at within-subject comparisons of those students who had experience with both online and face-to-face courses, and betweensubject comparisons of those students who had experience with only one mode of delivery. The within subject comparison revealed that more students admitted to cheating in online classes. The between subject comparisons revealed a smaller rate of cheating for students who only took online courses. However, when the authors controlled for age, the difference between the two groups became insignificant.

The two articles that revealed no differences between self-reported cheating behaviors between face-to-face courses and online courses are Grijalva et al. (2006) and Watson and Sottile (2010). Grijalva et al. (2006) used a randomized response method to gather data from 796 undergraduate students who took an online course and estimated a three percent rate of cheating. The authors concluded that this rate of cheating is consistent with the level of cheating in a face-to-face classroom from a single class (Kerkvliet and Sigmund, 1999; Karlins, Michaels, and Podlogar, 1988). Watson and Sottile (2010, p.5) examined self-reported cheating behavior of undergraduate and graduate students and the results of their student survey revealed that '32.1 percent admitted to having cheated in a live class and 32.7 percent admitted to cheating in an on-line class at some point in their higher education coursework.' Thus, the response rates do not reveal a discernable difference in cheating behaviors between the two modes of delivery.

Kidwell and Kent (2008, p.S9) used 248 survey responses from online students and 210 from face-to-face students to compare cheating behaviors of the two groups. Of the face-to-face students, 78 percent admitted to cheating at least once whereas only 35 percent of the online students reported that they ever cheated. The authors noted however, that the average age of the online students was 35.8 compared to 22.4 for face-to-face students. In addition, 78.2 percent of the online students were female compared to 68.4 percent female in the face-to-face group. Because of these differences, the authors controlled for age and gender in their analysis and concluded that 'study mode itself explains differential rates of cheating beyond the influence of age or gender.'

Stuber-McEwen, Wisely, and Hoggatt (2009, p.2) surveyed 225 undergraduate students (87 online and 138 offline) and found that 'students in this sample were more likely to cheat in traditional classroom settings and less likely to cheat in online courses.' The authors also noted that age could be a confounding factor since most of the online classes surveyed are offered through their school's adult program whose participants are on average older.

As mentioned previously, Hart and Morgan (2010) used survey responses from 44 students in a registered nurse to baccalaureate in nursing (RN-BSN) program and 330 students in the same RN-BSN program that was conducted fully online to compare academic dishonesty in the two formats. The results showed the traditional classroom RN-BSN students reporting higher levels of cheating compared with the online students. However, the authors note that the higher levels of reported cheating in the traditional format dealt mostly with collaborative cheating behaviors. Since online students do not interact with each other as much as face-to-face students do, this may explain why they reported less of these types of cheating behaviors.

Peled et al. (2019) used survey responses from 841 U.S. students and 1,634 Israli students in both online and face-to-face courses to assess their personality and willingness to engage in academic misconduct. The findings 
indicated that in both countries, dishonest behaviors are greater in face-to-face courses than in online courses. The authors suggested that their results are consistent with the notion that students in online courses may have higher levels of intrinsic motivation to learn or are able to learn independently which reduces their desire to cheat (Zhang, 1998).

\section{How cheating behaviors differ within proctored and unproctored environments}

There are 15 studies that used an experimental (randomized or observational) design to compare cheating behaviors in an unproctored versus proctored environment. It should be noted that at the time of this study, proctoring software was still in its infancy and many online instructors were still conducting unproctored assessments. As proctoring software becomes more readily available and affordable, future research should focus on how proctoring software impacts student and faculty perceptions of academic dishonesty in the online environment.

The articles are discussed below and grouped first by the type of experimental design and then within each design by the authors' results.

\subsection{Randomized experimental designs}

There are three articles that employed a randomized experimental design to compare online cheating behaviors in proctored and unproctored testing environments and one study that used a randomized experimental design to compare cheating behaviors in a proctored in-class testing site to an online unproctored testing site.

Hollister and Berenson (2009) examined 217 students enrolled in one of two sections of an introductory computer literacy course. The only difference between the two sections was how the exams were administered. Both sections took their exams online, however, in one randomly assigned section, the exam was given in a classroom with a proctor and in the other section it was taken offsite without a proctor. The results showed that although the unproctored environment had 'significantly more variation in their performance results,' there was no evidence of cheating behaviors in this setting (Hollister and Berenson, 2009, p.290).

Fask, Englander, and Wang (2014) improved upon Hollister and Berenson (2009) by accounting for the confounding effects of taking an online exam. More specifically Fask, Englander, and Wang (2014) used an experimental design and controlled for the increased opportunities to cheat in the online environment as well as the physical and psychological differences between proctored in-class testing and unproctored online testing. The results of their study using 44 students from two sections of an introductory statistics course indicated that students taking the online exam have a greater propensity to exhibit cheating behaviors. It is important to note that the author's approach was not technically a randomized design, but they believed the assignment of students to each type of testing was effectively random.

A related study by Alessio et al. (2018) used a randomized design in six sections of an online medical terminology course to examine students' quiz scores and the time taken to complete them. To investigate the impact of proctoring software on student performance, students were assigned a sequence of four proctored and unproctored online quizzes. For example, one sequence could be proctored, proctored, unproctored, unproctored, while another sequence could be unproctored, unproctored, proctored, proctored. The study controlled for exam difficulty, course design, instructor effects, and student majors. The results indicated that students who were tested without proctoring software took more time to complete the quizzes and scored better on average (7-9 points on a 100 point quiz). The authors concluded that the unproctored students were likely using the extra time to look up answers using prohibited resources.

Hylton (2016) randomly assigned 270 undergraduate students enrolled in the same course at a private university to either a treatment or control group. All students took their exams online from the same pool of questions. The treatment group was monitored via webcam by a Web-based proctor, while the control group was unmonitored. The results showed no statistically significant difference between the two sets of test scores although those students who took the unproctored exam had slightly higher scores. In addition, the unproctored students took significantly longer to complete the exam. The author concluded that one explanation for this result could be that the unmonitored students perceived a greater opportunity to engage in dishonest behavior than those who were monitored. 
Overall, when confounding factors are controlled for, the results of the randomized experimental studies point to higher levels of cheating that may be correlated with the unproctored environment.

\subsection{Observational Designs}

Although there are many observational studies in the literature that reveal higher exam scores of students in unproctored versus proctored environments, not all of these studies attribute their findings to cheating behaviors (Prince et al. (2009); Carstairs and Myors, (2009). In contrast, the 11 studies reviewed in this paper all reference cheating as part of the analysis.

Yates and Beaudrie (2009) studied 850 grades from a variety of distance education mathematics courses and compared 406 students who were evaluated in a proctored testing environment with 444 students who were evaluated fully online with unproctored testing and found no significant difference in grades between the two groups. However, this paper was later critiqued by Englander, Fask, and Wang (2011) for not including a uniform set of techniques to suppress cheating, for not accounting for selection bias and changes in online resources over time, for using an inappropriate outcome measure, and for overstating their conclusions.

Beck (2014) employed a statistical model to predict academic dishonesty using student scores ( 80 proctored and 19 unproctored) on mid-term and final exams from three sections of an introductory course with the same instructor in the same semester. The model controls for student ability, academic ranking, major, and age. The author concluded that students in online courses with unproctored testing are no more likely to cheat on an examination than proctored students in a hybrid or face-to face-course. In addition, the author also noted that there is no evidence that students with lower GPA's are more likely to enroll in online courses which was suggested by Englander, Fask, and Wang (2011).

Ladyshewsky (2015) used a sample of 250 post-graduate students enrolled in a management and leadership course and observed no increase in the mean test scores overtime for those students who took an unsupervised online multiple-choice test compared to those students who took the multiple-choice test in a supervised classroom. The author concluded that concerns about increased cheating in the online format are not supported. Similarly, Peng (2007) analyzed the multiple-choice test scores of 65 undergraduate students in a corporate finance course and 69 undergraduate students from an investments course. In this study, five quizzes were administered online and a sixth was administered in a proctored classroom. The author found no statistically significant differences in multiple-choice test scores between the in-class and online testing formats and concludes that the online format of quizzes did not make it easier to cheat.

Metz (2008) analyzed quiz performance from two large undergraduate biology courses. Although the courses in this study were taught in a traditional face-to-face lecture format, some quizzes were conducted online. Specifically, 90 students took online quizzes and 98 students took in-class quizzes. The authors looked for evidence of 'information leaks' but show that students who waited until later to take the quizzes scored 10-15 percent lower than those who took the quizzes earlier. The authors also compared the online quiz scores to a previous year's in-class quiz scores and found no significant difference between the average scores in the two formats. The author concluded that as long as preventative measures are taken to discourage cheating, online assessment scores will not be influenced by acts of academic dishonesty.

Harmon and Lambrinos (2008) compared the incidence of cheating between proctored and unproctored exams in an online class using a sample of 60 students in paired sections of a principles of economics course. The only significant difference between the two sections is that in one section the 30 question (multiple choice) final exam was proctored and in the other section it was not. Students did not know prior to enrolling in the course whether their final would be proctored or unproctored. To detect cheating, the authors controlled for the student's cumulative GPA at the beginning of the semester, age, academic major, and college grade level and compared the R-squared statistic for each exam. The authors concluded that cheating is evident because the control variables 'did not explain nearly as much of the variation in test scores in the unproctored format as they did in the proctored format,' Harmon and Lambrinos (2008, p.123).

To improve upon the model used by Harmon and Lambrinos (2008), Fask, Englander, and Wang (2015) employed a latent variable model to analyze the cheating patterns of 52 undergraduate students taking an introductory statistics course. The authors observed that GPA (as mentioned previously) and attendance (mastery variables) are related to cheating. This implies that class attendance and GPA 'become less important predictors of grades 
when students can more easily cheat on an online exam than they are when students' cheating opportunities are limited by a proctored exam' (Fask, Englander, and Wang, 2015, p.8). The authors concluded that although 'cheating is the most reasonable interpretation of the latent variable,' (Fask, Englander, and Wang, 2015, p.9) the testing environment itself may also explain a higher level of performance in an unproctored setting.

Arnold (2016) also attempted to improve upon the Harmon and Lambrinos (2008) model by employing an algorithm developed by Jacob and Levitt (2003) to detect 'unexpected fluctuations in test results' Arnold (2016, p.101) using data from 461 students who took proctored exams in mathematics and unproctored online exams in microeconomics, statistics, and accounting. The author revealed that the 'ability of human capital variables to explain the variation in unproctored test grades is slightly lower than their ability to explain proctored test grades' Arnold (2016, p.105). In addition, they also found that cheating is more likely to occur in the unproctored setting than the proctored setting.

Daffin and Jones (2018) analyzed data from 1,694 undergraduate students taking online psychology classes ranging in difficulty level. The authors noted that the typical online student in their study is a working adult in their 30 s or 40 s with a family coming back to study after being out of school for a period of time. The authors revealed that 'the mean percentage earned on proctored exams was significantly lower than the percentage earned on non-proctored exams' Daffin and Jones (2018, p.138). They also found that students took almost twice as long on unproctored exams as they did on proctored exams. The authors concluded that cheating is one possible explanation for such findings but also suggested the findings could be related to general test anxiety.

Richardson and North (2013) analyzed exam scores from three undergraduate courses and one graduate course. Specifically, they compared 11 proctored exams against 22 identical unproctored exams and found that the class average on the unproctored exam was higher for 19 out of 22 cases. In addition, the difference was statistically significant in 15 of those cases. The authors concluded that this finding is 'a strong indicator of significant cheating' Richardson and North (2013, p.270).

Alessio et al. (2017) used a natural design study of 147 students enrolled in nine sections of the same undergraduate online course to test whether online quiz results were lower when proctored than when unproctored. In the study, instructors from four sections of the course used either a proctoring software called Software Secure or one called Respondus Monitor. The results indicated that students took significantly more time to complete their online quizzes and quiz scores were on average 17 points higher when students were not proctored using video monitoring. The authors concluded that this difference is large enough to suggest that students may resort to academic dishonesty when not being proctored during online assessments.

It should be noted that since observational studies can only establish that associations exist between higher test scores and cheating but cannot establish a cause-and-effect relationship, the results of the observational studies reviewed above should be viewed with caution. In addition, since about half of the studies did not find a significant relationship between test scores and cheating and the other half of the studies did, the ability to generalize the results is limited.

\section{Discussion}

The strand of literature that considers academic dishonesty from on online perspective is currently in its infancy, especially when you think of it relative to the literature on academic dishonesty in general. There are several papers reviewed here that have made significant contributions and have provided meaningful results. However, there are still many topics and issues that need further investigation. By going back to the four major themes covered in this review, the gaps in the literature can be better defined.

The first major category reviewed was the factors that contribute to cheating behaviors. These factors were broken down into two categories: individual factors and situational factors. Papers that considered individual factors from the face-to-face perspective were examined briefly for comparison purposes. In both the face-toface and online environments, younger students are found to engage in cheating behaviors more often while those students with higher GPA's are found to cheat less. It should be noted however, that because of the small number of papers that examine individual factors for online students, and given the overall mixed results, 
generalizations should be considered with caution. In addition, since only one study focused exclusively on students in online courses, additional research in this area is warranted.

For the situational factors, many issues from the face-to-face environment have been examined such as student culture, time constraints, risk and punishment, as well as academic entitlement. Unfortunately, the literature pertaining to situational factors for online cheating is scarce and limited in scope. For example, there are three papers, Costley (2017), Arnold (2016) and Brent and Atkisson (2011) that suggest student dissatisfaction as a result of poor course design influences online cheating behaviors. However, Arnold (2016) did not test this result directly but instead offered student dissatisfaction as an explanation for poor performance, Costley (2017) only looks at one specific cheating behavior, and Brent and Atkisson (2011) only sampled a single class. In addition, although Bretag et al. (2018) do consider mode of study as a contributing factor to cheating, as the authors point out, the percentage of online students are under-represented in their sample and therefore results should be interpreted with caution. Given the relevance of situational factors for explaining cheating behaviors in the faceto-face classroom, this topic needs to become a priority in the online literature as well. In particular, researchers should consider how situational factors in the online environment can be explained using deterrence theory, neutralization theory, and academic entitlement. By focusing on and exploring these relationships, online instructors could gain insights for improving course design.

The second theme covered in this review are the student and faculty perceptions of online cheating behaviors. Given the mixed results and small number of papers available on these topics, additional research that considers specific cohorts of students and faculty in this area would be beneficial. For example, do student perceptions differ based on age, gender, field of study, college level, experience with online courses, and do faculty perceptions differ based on field of study, years of online teaching experience, types of assignments and assessments used (course design), and so on. Finally, given that many students perceive there to be increased opportunities to cheat in the online environment, it is important that future research focus on how technology can continue to improve student-teacher relationships in this setting to help circumvent these issues.

The third theme reviewed in this paper considered the prevalence of cheating online compared to traditional cheating in the classroom. The results of the self-reported surveys did not provide a definitive conclusion when comparing cheating behaviors in the two environments. However, the studies did reveal that confounding factors such as age, gender and experience taking online courses can influence the results. It should also be noted that various concerns have been raised about the validity of self-reported surveys of student cheating (Baumeister, Vohs, and Funder, (2007); Porter, (2011). For example, social desirability bias predicts that respondents deny socially undesirable behaviors but admit to socially desirable behaviors (Randall and Fernandes, (1991) leading to underreported levels of academic misconduct as suggested by Miller, Shoptaugh, Parkerson (2008). However, given the nature of the topic, self-reported surveys are still an important tool for analyzing cheating behaviors. Once again, additional research on a larger scale comparing online and traditional cheating in the classroom would be beneficial for online instructors.

The last theme discussed in this paper deals with cheating behaviors in proctored versus unproctored environments. This is an especially important topic as proctoring software is becoming more readily available. There are four papers that use a randomized design to examine cheating behaviors. Three out of the four papers find that unproctored students are more likely to engage in dishonest behavior. However, Fask, Englander, and Wang (2014) used a small sample of 44 students and although the results of the paper revealed that "online testing does facilitate student cheating," the authors cautioned that the methodology they used needs to be tested in a large class situation to determine if the results can be replicated. Additional research employing experimental designs will be extremely useful in determining the need and future demand for proctoring software in online courses.

In addition to the experimental designs, there were also 11 papers reviewed that studied the proctored and unproctored environments using observational studies. The results of these studies are also mixed, however, many of these studies should be interpreted with caution as many of them had small sample sizes. More specifically, seven out of 11 had samples of less than 100. Of the remaining four that had larger sample sizes, three of those papers concluded that cheating is more likely in the unproctored setting. When conducting future research using observational designs, studies using larger sample sizes that control for confounding factors will add more depth to the online academic dishonesty literature. 


\section{Conclusion}

Academic dishonesty in higher education has been a topic of concern for many decades. The research analyzing this topic is abundant, covering many aspects of cheating behaviors in the face-to-face classroom. In addition, many researchers claim that online learning provides a new set of opportunities for students to engage in dishonest behavior and therefore creates a new set of challenges for teachers as they design their online courses. Given the growth of online learning in higher education, it is important to understand how cheating behaviors have changed and adapted to this new environment. The goal of this paper was to examine how cheating in the online environment has thus far been addressed in the literature and to make suggestions for future research where gaps in the research are found to exist.

The paper is organized into four major themes. The first theme reviews the individual and situational factors that have been found to contribute to cheating in the online learning environment. The papers that analyzed the relationship between individual factors and academic dishonesty in the online environment revealed mixed results with only age and GPA being mentioned as contributing factors in more than one study. This is in contrast to the face-to-face studies that found age, gender and intellectual ability to affect cheating behaviors more consistently. It was suggested that additional research is needed in this area to better understand the individual factors related to online cheating behaviors.

When considering the situational factors related to academic dishonesty in the online environment, anonymity and student perceptions are found to be important factors influencing dishonest behavior both directly and indirectly. Anonymity can be both a challenge for teachers and an opportunity for students because online learning can prevent a personal connection from forming between the students and teachers. This can lead to feelings of isolation, dissatisfaction with course design, and an increased perception of cheating opportunities. It was suggested that future research on situational factors in the online environment be examined more formally on a larger scale using already accepted theories from the traditional learning environment.

The next section of the paper focuses on the second theme: student and faculty perceptions of online cheating behaviors. The papers reviewed on this topic also revealed mixed results. About half the papers claimed that students believe cheating is more prevalent or easier online. The other papers are either inconclusive or found the opposite to be true. Future research that considers how these perceptions are formed and what factors contribute to these perceptions was suggested. In addition, although the papers looking at faculty perceptions were also inconclusive, they did reveal that experience teaching online courses has an impact on beliefs. Specifically, faculty with experience teaching online observed cheating to be no more pervasive in this environment compared to the face-to-face setting. It is also interesting to note that Hard, Conway, and Moran (2006) argued that the efforts taken to prevent student cheating are related to faculty perceptions about academic misconduct. Specifically, they believe that faculty are more likely to take measures to prevent cheating when they perceive cheating to be more frequent and will be more likely to confront students about the suspected misconduct. Since in general, the faculty who have experience teaching online do not see a significant difference between the levels of cheating in a face-to-face environment versus online, future research should focus on how faculty perceptions of online cheating are related to the various cheating deterrence mechanisms implemented in this environment. Some examples of deterrence mechanisms include: proctoring software, biometrics, honor codes, high penalties for cheating, time limits on assessments, and randomizing examination questions.

The third section of this paper reviews the literature comparing the prevalence of cheating online to cheating in the classroom using eight self-reported surveys. Overall, two articles found that cheating is more prevalent online, two found no difference, and four reported cheating to be less prevalent online. Although self-reported surveys are an important tool for analyzing sensitive subjects such as cheating, they must be evaluated carefully due to an inherent bias that causes students to underreport bad behavior.

The fourth and final section of this paper considers 15 articles that used experimental designs to compare cheating behaviors in proctored versus unproctored environments. Four of these papers used a randomized experimental design and when confounding effects are accounted for, the results revealed that unproctored assessments can lead to higher levels of suspected cheating. The remaining 11 papers are observational studies. The results of the observational studies are mixed but those with larger sample sizes seemed to suggest that cheating is more prevalent in the unproctored environment. Given this result, additional research that studies 
online proctoring tools and services would be valuable to instructors specifically, and to colleges and universities in general.

Overall this paper provides a review of the literature that relates the extensively studied topic of academic dishonesty in the classroom to the relatively new issue of online learning in higher education. Although many of the factors that influence student cheating behaviors in the face-to-face environment are also relevant in the online environment, the ways in which these factors are perceived and addressed are often different. In addition, due to the mixed results found in both the perceptions of cheating as well as the actual cheating studies, further empirical research is especially important to better understand cheating in the online environment. In particular, more studies employing randomized experimental designs are needed to gauge the levels of online cheating and to help teachers better understand how they can address academic misconduct in their courses.

\section{References}

Alessio, H.M., Malay, N.J., Maurer, K.T., Bailer, A.J., and Rubin, B., 2017. Examining the effect of proctoring on online test scores. Online Learning, 21(1), pp.146-161.

Alessio H.M., Malay N., Maurer K., Bailer A., and Rubin, B., 2018. Interaction of proctoring and student major on online test performance. International Review of Research in Open and Distributed Learning, 19(5), pp.166-185.

Allen, I.E., and Seaman, J., 2015. Grade level: tracking online education in the United States. Babson Survey Research Group and Quahog Research Group, LLC. Last access on February 3, 2019: http://www.onlinelearningsurvey.com.

Arnold, I., 2016. Cheating at online formative tests: does it pay off? Internet and Higher Education, 29, pp.98-106.

Athanasou, J., and Olasehinde, O., 2002. Male and female differences in self-report cheating. Practical Assessment Research and Evaluation, 8(5), pp.1-12.

Auer, N., and Krupar, E., 2001. Mouse click plagiarism: the role of technology in plagiarism and the librarian's role in combating it. Library Trends, Winter 49 (3), pp.415-432.

Baumeister, R., Vohs, K., and Funder, D., 2007. Psychology as the science of self-reports and finger movements: whatever happened to actual behavior? Perspectives on Psychological Science, 2(4), pp.396-403.

Beasley, E. M., 2014. Students reported for cheating explain what they think would have stopped them. Ethics and Behavior, 24(3), pp.229-252.

Beck, V., 2014. Testing a model to predict online cheating - much ado about nothing. Active Learning in Higher Education, 15(1), pp.65-75.

Bedford, D.W., Gregg, J., and Clinton, M.S., 2011. Preventing online cheating with technology: a pilot study of remote proctor and an update of its use. Journal of Higher Education Theory and Practice, 11(2), pp.41-58.

Black, E. W., Greaser, J., and Dawson, K., 2008. Academic dishonesty in traditional and online classrooms: does the "media equation" hold true? Journal of Asynchronous Learning Networks, 12(3-4), pp.23-30.

Brent, E., and Atkisson, C., 2011. Accounting for cheating: an evolving theory and emergent themes. Research in Higher Education, 52(6), pp.640-658.

Bretag, T., Harper, R., Burton, M., Ellis, C., Newton, P., Rozenberg, P., Saddiqui, S., and Haeringen, K., 2018. Contract cheating: a survey of Australian university students. Studies in Higher Education, doi: 10.1080/03075079.2018.1462788.

Brimble, M., and Stevenson-Clarke, P., 2005. Perceptions of the prevalence and seriousness of academic dishonesty in Australian universities. Australian Educational Researcher, 32(3), pp.19-44.

Brimble, M., and Stevenson-Clarke, P., 2006. Managing academic dishonesty in Australian universities: Implications for teaching, learning and scholarship. Accounting, Accountability and Performance, 12(1), pp.32-63.

Buckley, M. R., Wiese, D.S., and Harvey, M., 1998. An investigation into the dimensions of unethical behavior. Journal of Education for Business, 73(5), pp.284-290.

Carstairs, J., and Myors, B., 2009. Internet testing: A natural experiment reveals test score inflation on a high-stakes, unproctored cognitive test. Computers in Human Behavior, 25(3), pp.738-742.

Chapman, K. J., Davis, R., Toy, D., and Wright, L., 2004. Academic integrity in the business school environment: I'll get by with a little help from my friends. Journal of Marketing Education, 26(3), pp.236-249.

Charlesworth, P., Charlesworth, D. D., and Vician, C., 2006. Students' perspectives of the influence of web-enhanced coursework on incidences of cheating. Journal of Chemical Education, 83(9), pp.1368-1375.

Cizek, G., 2003. Detecting and preventing classroom cheating: promoting integrity in assessment. Experts in Assessment. Corwin Press, Inc., A Sage Publications Company, Thousand Oaks, CA.

Clarke, R., and Lancaster, T., 2006. Eliminating the successor to plagiarism? Identifying the usage of contract cheating sites. Proceedings of $2^{\text {nd }}$ International Plagiarism Conference, doi:10.1.1.120.5440.

Costley, J., and Lange, C., 2017. The mediating effects of germane cognitive load on the relationship between instructional design and students' future behavioral intention. Electronic Journal of e-Learning, 15(2),pp.174-187.

Costley, J., 2018. Student perceptions of academic dishonesty at a cyber-university in South Korea. Journal of Academic Ethics. https://doi.org/10.1007/s10805-018-9318-1 (Published online 17 November 2018) 
Cronan, T. P., Mullins, J. K. and Douglas, D. E., 2018. Further understanding factors that explain freshman business students' academic integrity intention and behavior: plagiarism and sharing homework. Journal of Business Ethics, 147(1), pp.197-220.

Crown, D. F., and Spiller, S. M., 1998. Learning from the literature on collegiate cheating: a review of empirical research. Journal of Business Ethics, 17, pp.683-700.

Daffin, Jr., L.W., and Jones, A. A., 2018. Comparing student performance on proctored and nonproctored exams in online psychology courses. Online Learning, 22(1), pp.131-145.

Englander, F., Fask, A., and Wang, Z., 2011. Comment on 'The impact of online assessment on grades in community college distance education mathematics courses' by Ronald W. Yates and Brian Beaudrie. The American Journal of Distance Education, 25(2), pp.114-120.

Engler, J., Landau, J., and Epstein, M., 2008. Keeping up with the Joneses: students' perceptions of academically dishonest behavior. Teaching of Psychology, 35(2), pp.99-102.

Ewing, H., Anast, A., and Roehling, T., 2016. Addressing plagiarism in online programmes at a health sciences university: a case study. Assessment and Evaluation in Higher Education, 41(4), pp.575-585.

Fask, A., Englander, F., and Wang, Z., 2014. Do online exams facilitate cheating? An experiment designed to separate out possible cheating from the effect of the online test taking environment. Journal of Academic Ethics, 12(2), pp.101112.

Fask, A., Englander, F., Wang, Z., 2015. On the integrity of online testing for introductory statistics courses: a latent variable approach. Practical Assessment Research and Evaluation, 20(10), pp.1-12.

Grijalva, T.C., Nowell, C., and Kerkvliet, J., 2006. Academic honesty and online courses. College Student Journal, 27(3), pp.180-185.

Hard, S.F., Conway, J., and Moran, A.C., 2006. Faculty and college student beliefs about the frequency of student academic misconduct. The Journal of Higher Education, 77(6), pp.1058-1080.

Harmon, O. R., Lambrinos, J., and Buffolino, J., 2010. Assessment design and cheating risk in online instruction. Online Journal of Distance Learning Administration, 13(3), pp.23-33.

Harmon, O. R., and Lambrinos, J., 2008. Are online exams an invitation to cheat? Journal of Economic Education, 39(2), pp.116-125.

Hart, L., and Morgan, L., 2010. Academic integrity in an online registered nurse to baccalaureate in nursing program. The Journal of Continuing Education in Nursing, 41(11), pp.498-505.

Heberling, M., 2002. Maintaining academic integrity in on-line education. Online Journal of Distance Learning Administration, 5(2), pp.1-6.

Hollis, L., 2018. Ghost-students and the new wave of online cheating for community college students. New Directions for Community Colleges, 2018 (183), pp. 25-34.

Hollister, K., and Berenson, M., 2009. Proctored versus unproctored online exams: studying the impact of exam environment on student performance. Decision Sciences Journal of Innovative Education, 7(1), pp.271-294.

Hylton, K., Levy, Y., and Dringus, L. P., 2016. Utilizing webcam-based proctoring to deter misconduct in online exams. Computers and Education, 92-93, pp.53-63.

Iyer, R., and Eastman, J. K., 2006. Academic dishonesty: Are business students different from other college students? Journal of Education for Business, 82(2), pp. 101-110.

Jacob, B.A., and Levitt, S.D., 2003. Rotten apples: An investigation of the prevalence and predictors of teacher cheating. The Quarterly Journal of Economics, 118(3), pp. 843-877.

Karlins, M., Michaels, C., and Podlogar, S., 1988. An empirical investigation of actual cheating in a large sample of undergraduates. Research in Higher Education, 29(4), pp. 359-364.

Kasprzak, J., and Nixon, M., 2004. Cheating in cyberspace: maintaining quality in online education. Association for the Advancement of Computing In Education, 12(1), pp. 85-99.

Kelley, K., and Bonner, K., 2005. Digital text, distance education and academic dishonesty: faculty and administrator perceptions and responses. Journal of Asynchronous Learning Networks, 9(1), pp. 43-52.

Kennedy, K., Nowak, S., Raghuraman, R., Thomas, J., and Davis, S.F., 2000. Academic dishonesty and distance learning: student and faculty views. College Student Journal, 34(2), pp. 309-314.

Kerkvliet, J., and Sigmund, C. L., 1999. Can we control cheating in the classroom? Journal of Economic Education, 4(Fall), pp. 331-343.

Kidwell, L.A., and Kent, J., 2008. Integrity at a distance: a study of academic misconduct among University students on and off campus. Accounting Education, 17(1), pp. S3-S16.

King, C.G., Guyette, R.W., and Piotrowski, C., 2009. Online exams and cheating: an empirical analysis of business students' views. The Journal of Educators Online, 6(1), pp.1-11.

Kisamore, J. L., Stone, T. H., and Jawahar, I. M., 2007. Academic integrity: the relationship between individual and situational factors on misconduct contemplations. Journal of Business Ethics, 75(4), pp.381-394.

Ladyshewsky, R.K., 2015. Post-graduate student performance in 'supervised in-class' versus 'unsupervised online' multiple choice tests: implications for cheating and test security. Assessment and Evaluation in Higher Education, 40(7), pp.883-897.

Lanier, M., 2006. Academic integrity and distance learning. Journal of Criminal Justice Education, 17(2), pp.244-261.

Lau, L. K., and Haug, J. C., 2011. The impact of sex, college, major, and student classification on students' perception of ethics. Mustang Journal of Business and Ethics, 2, pp.92-105. 
McCabe, D. L., 2009. Academic dishonesty in nursing schools: an empirical investigation. The Journal of Nursing Education, 48(11), pp.614-623.

McCabe, D. L., and Trevino, L. K., 1997. Individual and contextual influences on academic dishonesty: a multi-campus investigation. Research in Higher Education, 38(3), pp.379-396.

McCabe, D. L., Trevino, L. K., and Butterfield, K. D., 2001. Dishonesty in academic environments. Journal of Higher Education, 72, pp.29-45.

McCabe, D. L., Butterfield, K. D., and Trevino, L. K., 2012. Cheating in college: Why students do it and what educators can do about it. Baltimore, MD: Johns Hopkins University Press.

McCabe, D. L., 1992. The influence of situational ethics on cheating among college students. Sociological Inquiry, 62, pp.365-374.

McCabe, D. L., Trevino, L. K., and Butterfield, K. D., 1999. Academic integrity in honor code and non-honor code environments: a qualitative investigation. The Journal of Higher Education, 70(2), pp.211-234.

McMurtry, K., 2001. E-cheating: combating a 21st century challenge. T.H.E. Journal, 29(4), pp.36-38, pp.40-41.

McNabb, L., and Olmstead, A., 2009. Communities of integrity in online courses: faculty member beliefs and strategies. Journal of Online Learning and Teaching, 5(2), pp.208-221.

Meng, C.L., Othman, J., D'Silva, J.L., and Omar, Z., 2014. Influence of neutralization attitude in academic dishonesty among undergraduates. International Education Studies, 7(6), pp.66-73.

Metz, A., 2008. The effect of access time on online quiz performance in large biology lecture courses. Biochemistry and Molecular Biology Education, 36(3), pp.196-202.

Miller, A., Shoptaugh, C., and Parkerson, A., 2008. Under reporting of cheating in research using volunteer college students. College Student Journal, 42(2A), pp.326-339.

Miller, A., and Young-Jones, A. D., 2012. Academic integrity: Online classes compared to face-to-face classes. Journal of Instructional Psychology. 39(3/4), pp.138-145.

Miller, B. K., 2013. Measurement of academic entitlement. Psychological Reports: Sociocultural Issues in Psychology, 113(2), pp.654-674

Newton, P., 2015. Academic integrity: A quantitative study of confidence and understanding in students at the start of their higher education. Assessment and Evaluation in Higher Education, 41(3): pp.482-497.

Ngo, K. L., Juliana, M. N., Jawanees, A. H. N., Salihah, A., Norhamimah, R., and Nafizi, I. M. A., 2018. Academic dishonesty among the Computer Science students in an English critical reading course. Journal of Fundamental and Applied Sciences, 10(2S), pp.540-553.

Owunwanne, D., Rustagi, N., and Dada, R., 2010. Students' perceptions of cheating and plagiarism in higher institutions. Journal of College Teaching and Learning, 7(11), pp.59-68.

Peled, Y., Eshet, Y., Barczyk, C., and Grinautski, K., 2019. Predictors of academic dishonesty among undergraduate students in online and face-to-face courses. Computers and Education, 131, pp.49-59.

Peng, Z., 2007. Giving online quizzes in corporate finance and investments for a better use of seat time. The Journal of Educators Online, 4(2), pp.1-18.

Porter, S., 2011. Do college student surveys have any validity? The Review of Higher Education, 35(1), pp.45-76.

Prince, D.J., Fulton, R. A., and Garsombke, T. W., 2009. Comparisons of proctored versus non-proctored testing strategies in graduate distance education curriculum. Journal of College Teaching and Learning, 6(7), pp.51-62.

Raines D.A., Ricci P., Brown S.L., Eggenberger T., Hindle T., and Schiff, M., 2011. Cheating in online courses: the student definition. The Journal of Effective Teaching, 11(1), pp.80-89.

Randall, D., and Fernandes, M., 1991. The social desirability response bias in ethics research. Journal of Business Ethics, 10(11), pp.805-817.

Richardson, R., and North, M., 2013. Strengthening the trust in online courses: a common sense approach. Journal of Computing Sciences in Colleges, 28(5), pp.266-272.

Rowe, N. C., 2004. Cheating in online student assessment: beyond plagiarism. Online Journal of Distance Learning Administration, 7(2), pp.1-10.

Ryan, G., Bonanno, H., Krass, I., Scouller, K., and Smith, L., 2009. Undergraduate and postgraduate pharmacy students' perception of academic dishonesty and plagiarism. American Journal of Pharmaceutical Education, 73(6), p.105.

Sande, C.van de, and Xuetao, L., 2018. Perceptions of cheating on in person and online mathematics examinations. International Journal of Arts Humanities and Social Sciences, 3(9). pp.28-35.

Seaman, J. E, Allen, I., and Seaman, J., 2018. Grade increase: Tracking distance education in the United States. Babson Park, MA: Babson Survey Research Group, Babson College. Last access on March 22, 2019: https://onlinelearningsurvey.com/reports/gradeincrease.pdf.

Şendağ, S., Duran, M., and Fraser, M. R., 2012. Surveying the extent of involvement in online academic dishonesty (edishonesty) related practices among university students and the rationale students provide: one university's experience. Computers in Human Behavior, 28(3), pp.849-860.

Shachar, M., and Neumann, Y., 2010. Twenty years of research on the academic performance differences between traditional and distance learning: summative meta-analysis and trend examination. MERLOT Journal of Online Learning and Teaching, 6(2), pp.318-334.

Simha, A., Cullen, J., 2012. A comprehensive literature review on cheating. International Journal of Cyber Ethics in Education, 2(4), pp.24-44. 
Simon, C. A., Carr, J. R., McCullough, S. M., Morgan, S. J., Oleson, T., and Ressel, M., 2004. Gender, student perceptions, institutional commitments and academic dishonesty: who reports in academic dishonesty cases? Assessment and Evaluation in Higher Education, 29(1), pp.75-90.

Smyth, L. M., and Davis, J. R., 2004. Perceptions of dishonesty among two-year college students: academic versus business situations. Journal of Business Ethics, 51(1), pp.62-73.

Spaulding, M., 2009. Perceptions of academic honesty in online vs. face-to-face classrooms. Journal of Interactive Online Learning, 8(3), pp.183-198.

Stiles, B. L., Wai Wong, N.C., and LaBeff, E., 2018. College cheating thirty years later: the role of academic entitlement. Deviant Behavior, 39(7), pp.823-834.

Stuber-McEwen, D., Wisely, P., and Hoggatt, S., 2009. Point, click, and cheat: frequency and type of academic dishonesty in the virtual classroom. Online Journal of Distance Learning Administration, 12(3), pp.1-10.

Styron, J., and Styron, Jr., and R. A., 2010. Student cheating and alternative web-based assessment. Journal of College Teaching and Learning, 7(5), pp.37-42.

Tennant, P., and Duggan, F., 2008. Academic misconduct benchmarking research project part 2. The recorded incidence of student plagiarism and the penalties applied. York: Higher Education Academy/JISC Academic Integrity Service.

Trenholm, S., 2006/2007. A review of cheating in fully asynchronous online courses: a math or fact-based course perspective [Electronic version]. Journal of Educational Technology Systems, 35(3), pp. 281-300. https://doi.org/10.2190/Y78L-H21X-241N-7Q02

Underwood, J., and Szabo, A., 2003. Academic offense and e-learning: individual propensities in cheating. British Journal of Educational Technology, 34(4), pp.467-477.

Vehviläinen, S., Löfström, E., and Nevgi, A., 2018. Dealing with plagiarism in the academic community: emotional engagement and moral distress. Higher Education, 75(1), pp.1-18.

Watson, G., and Sottile, J., 2010. Cheating in the digital age: Do students cheat more in online courses? Online Journal of Distance Learning Administration, 13(1), pp.1-13.

Watters, M. P., Robertson, P.J., and Clark, R.K., 2011. Student perceptions of cheating in online business courses. Journal of Instructional Pedagogies, 6, pp.1-14.

Whitley, B. E., Nelson, A.B., and Jones, C.J.,1999. Gender differences in cheating attitudes and classroom cheating behavior: A meta-analysis. Sex Roles, 41(9-10), pp.657-80.

Wideman, M., 2008. Academic dishonesty in postsecondary education: a literature review. Transformative Dialogues: Teaching and Learning Journal, 2(1), pp.1-12.

Yates, R. W., and Beaudrie B., 2009. The impact of online assessment on grades in community college distance education mathematics courses. The American Journal of Distance Education, 23(2), pp.62-70.

Zhang, P., 1998. A case study on technology use in distance learning. Journal of Research on Computing in Education, 30(4), pp.398-420. 